\title{
ESTUDO REGIONAL DA ADUBAÇÃO BORATADA DO ALGODOEIRO NO ESTADO DE SÃO PAULO ( ${ }^{1}$ )
}

\author{
NELSON MACHADO DA SILVA $\left({ }^{2,7}\right)$, LUIZ HENRIQUE CARVALHO $(2,7)$, EDERALDO \\ JOSE CHIAVEGATO ( $\left.{ }^{2}\right)$, JÚLIO ISAO KONDO ( $\left.{ }^{3}\right)$, ONDINO CLEANTE \\ BATAGLIA $\left({ }^{4,7}\right)$, RUTER HIROCE $\left({ }^{4,7}\right)$, NELSON BORTOLETTO $\left({ }^{5}\right)$ \\ O JOSE CARLOS SABINO $(\%)$
}

\begin{abstract}
RESUMO
Quinze experimentos de adubação boratada foram realizados em condiçőes de campo com o algodoeiro, em diferentes regiöes produtoras paulistas, no período de 1979-86. O micronutriente foi aplicado na adubaçăo do plantio, nas doses de 0,$0 ; 0,2$; 0,$4 ; 0,8 ; 1,6 \theta 3,2 \mathrm{~kg} / \mathrm{ha}$ de $B$, como bórax, em esquema estatístico de quadrado latino. Utilizaram-se sementes dos cultivares IAC 17, nos quatro primeiros anos, e IAC 20, nos demais. Na maioria dos experimentos, houve resposta favorável à adubação, em termos de produção, embora se tenham obtido em apenas três deles (20\% dos casos) diferenças estatisticamente significativas. Quanto à concentração de boro no limbo (quinta folha), ocorreu aumento significativo em seis dos onze ensaios amostrados (55\%). Reunindo os experimentos em função do histórico das glebas estudadas e da ocorrência de sintomas de deficiência ou de toxicidade de boro, discriminou-se muito bem o efeito geral da adubação. As mais altas produtividades foram alcançadas nos solos tradicionalmente cultivados e adubados e com a acidez corrigida. No entanto, a ação do micronutriente foi maior nos solos corrigidos e adubados com NPK, diminuindo para as glebas em fase de correção ou que já haviam recebido adubação boratada, sendo praticamente nula nos solos pouco cultivados, de pastagens. Observou-se uma relação significativa entre a produção e a concentração de B no solo, extraído pela solução de Mehlich ou, em especial, pela água quente, assim como entre a produção e a concentração de boro no limbo foliar. Como primeira aproximação, sugerem-se as faixas de 0,20 a 0,40ppm de B no solo (água quente), $\theta$ de 25 a 40ppm de $B$ no limbo da quinta folha, como indicadoras da necessidade de uso do boro na adubação do algodoeiro.
\end{abstract}

Termos de indexação: boro, estudo regional; algodão, produtividade e análise foliar; análise de solo; correlações.

(') Trabalho apresentado na VIReunião Nacional do Algodão, em Campina Grande (PB), dezembro de 1990. Recebido para publicação em 4 de março e aceito em 30 de setembro de 1991.

(2) Seção de Algodão do Instituto Agronômico (IAC), Caixa Postal 28, 13001 Campinas (SP).

(3) Seção de Tecnologia de Fibras, IAC.

(4) Seção de Fertilidade do Solo e Nutrição de Plantas, IAC.

(5) Estação Experimental de Votuporanga, IAC.

(6) Estação Experimental de Tietê, IAC.

(7) Com bolsa de pesquisa do CNPq. 


\title{
ABSTRACT \\ REGIONAL TESTS OF BORON FERTILIZATION ON COTTON
}

\begin{abstract}
After the confirmation of problems on cotton concerning boron nutrition in the State of São Paulo, Brazil, at the decade of 1970, experimental field tests were carried out and demonstrated the necessity of boron fertilization on deficient soils. With the purpose of evaluating the use of boron under different conditions, it was conducted a regional study through the São Paulo State cotton belt, during the period of 1979 to 1986. Rates of $0,0.2,0.4,0.8,1.6$ and $3.2 \mathrm{~kg} / \mathrm{ha}$ of $B$ as borax ( $11 \%$ of $B$ ), were applied at planting time, in latin square design experiments. The variety IAC 17 was used during the four years, followed by the IAC 20 . Boron fertilization consistently increased cotton yield, although statistically significant differences were obtained only in $20 \%$ of the events; the plants reacted better in terms of boron concentration in the leaf blade. Grouping the experiments by previous informations about use of liming and mineral manure, associated to the occurrence of boron deficiency or toxicity symptons, provided a good discrimination of B fertilization. The effect of boron was greater in tradicionally limed and fertilized (NPK) soils; it decreased on soils with acidity in phase of correction or corrected but previously fertilized with boron, and was negligible in crops after old pastures. There was a significant correlation relating cotton yield and soil boron determined with Mehlich solution $\left(\mathrm{HCl} 0.05 \mathrm{M}+\mathrm{H}_{2} \mathrm{SO}_{4} 0.0125 \mathrm{M}\right)$ or, specially, with hot water. Significant results were also observed in relation to yield and fifth leaf blade boron concentration. As a preliminary approach, analitycal values over ranges of $0.20-0.40 \mathrm{ppm}$ and $25-40 \mathrm{ppm}$ for soil boron extracted with hot water and for leaf blade boron concentration, respectively, were considered as indicative of the need for boron supplying in cotton fertilization.
\end{abstract}

Index terms: boron, regional tests; cotton, yield and foliar analysis; soil analysis; correlations.

\section{INTRODUÇÃO}

Segundo considerações de HINKLE \& BROWN (1966), devido ao fato de o boro ser normalmente removido em pequenas quantidades, sua deficiência costuma ocorrer em condições de alto consumo de fertilizantes em culturas de ciclo rápido, que tenham a maior porção da parte aérea removida com a colheita. Entretanto, sua disponibilidade é função de uma série de fatores. Por exemplo, enquanto a matéria orgânica parece ser a principal fonte de boro, em especial nos solos ácidos das regiões úmidas, o uso de corretivos de acidez do solo pode concorrer para diminuir sua disponibilidade. Por outro lado, esse micronutriente se mostra mais disponível em solo de textura arenosa, que o torna mais lixiviável em períodos chuvosos; no entanto, sintomas de carência têm sido relatados com maior freqüência em anos secos.

Em recente revisão, CARVALHO (1988) cita cerca de catorze trabalhos que relatam um efeito significativo da adubação boratada no algodoeiro cultivado em condições de campo. Somente alguns desses ensaios, no entanto, foram repetidos em diferentes glebas e anos agrícolas. SEDBERRY JR. et al. (1969), por exemplo, obtiveram aumentos significativos de produção em apenas três de quarenta e nove ensaios de campo. FRITZ (1971), por sua vez, obteve sucesso em um único ensaio, 
de sete realizados. MURPHY \& LANCASTER (1971), por fim, constataram aumentos significativos na produtividade, em três de seis estudos.

Após a constatação oficial da ocorrência de deficiência de boro em lavouras paulistas (COSTA et al., 1976), demonstrou-se experimentalmente que, em solos carentes, o seu uso era imprescindível (CARVALHO, 1980, SILVA et al., 1982), com indicações sobre os modos de aplicá-lo (CARVALHO, 1988). Buscando avaliar a resposta do algodoeiro a doses de boro, fornecidas na adubação de plantio em situações variáveis de carência da planta, projetou-se um estudo regional abrangendo as principais regiões produtoras de algodão do Estado de São Paulo.

\section{MATERIAL E MÉTODOS}

No período de $1979-86$, em diferentes regiões produtoras paulistas $\left({ }^{8}\right)$, foram realizados ensaios de campo visando avaliar a resposta do algodoeiro à aplicação de boro. O micronutriente foi fornecido no sulco de semeação, nas doses de 0,0; 0,$2 ; 0,4 ; 0,8 ; 1,6$ e 3,2kg/ha de B na forma de bórax (11\% de B), em mistura com $10-75-75 \mathrm{~kg} /$ ha de $\mathrm{N}, \mathrm{P}_{2} \mathrm{O}_{5}$ e $\mathrm{K}_{2} \mathrm{O}$, respectivamente, como sulfato de amônio (20\% de $\mathrm{N}$ ), superfosfato triplo ( $45 \%$ de $\left.\mathrm{P}_{2} \mathrm{O}_{5}\right)$ e cloreto de potássio $\left(60 \%\right.$ de $\left.\mathrm{K}_{2} \mathrm{O}\right)$. Excepcionalmente, no ensaio de Aguaí, em 1981/82, fez-se uma adubação suplementar com $160 \mathrm{~kg} / \mathrm{ha}$ da fórmula comercial 3-15-15, entre a semeação e a cobertura, por tratar-se de solo de cerrado em recuperação. Efetuaram-se duas adubações de cobertura com o sulfato de amônio, aplicando-se $30 \mathrm{~kg} / \mathrm{ha}$ de N, em cada uma, no desbaste e no início do florescimento.

Adotou-se o esquema em quadrado latino, com seis repetições, sendo os ensaios semeados com o cultivar IAC 17, nos quatro primeiros anos, e com o 'IAC 20', nos últimos; no ensaio de Aguaí, em 1981-82, utilizou-se 'IAC 19', por ter sido instalado em um campo de produção de sementes da Secretaria da Agricultura. As parcelas experimentais foram constituídas por quatro linhas de $0,5 \mathrm{~m}$ de comprimento, sendo apenas as centrais consideradas úteis para coleta de dados. $O$ espaçamento entre linhas variou de 0,8 a 1,0m, em função da fertilidade do solo; no desbaste, deixaram-se cerca de sete plantas por metro. No preparo do material para instalação de ensaios, pesou-se a quantidade de bórax correspondente a cada linha, em balança de precisão, antes de incorporá-lo à mistura de adubos N, P e K.

$\left({ }^{8}\right)$ Ensaios efetuados nas seguintes propriedades: Fazenda Piraporinha, de Brasil Ferreira Melo, em Conchal; sítio de Mário Avancini, em Moji Mirim; Fazenda Ranchão, de Massayuki Matsue, em São João das Duas Pontes; Fazenda São José, de José Toledo, em Nhandeara; Fazenda Campo Alegre, de Guilherme Rehder, em Aguaí; Campus da UNESP, em llha Solteira; Eståncia Wilma, de Moacir Carvalho, em Santa Cruz da Conceição; Fazenda Colorado, de Nicanor Carvalho e Plínio A.S. Leme, em Bernardino de Campos; Escritório Regional do IAC, em Guaíra; Sítio Santa Rosa do Bebedouro, de Jacob Sinotti e outros, em Pirassununga; propriedade de Antônio J. Borin, em Guará, e Sítio Bom Jesus, de Nicanor Carvalho e Plínio A.S. Leme, em Leme. 
Foram efetuadas análises da variância, individuais, dos dados de produção e da concentração de boro no limbo foliar de amostras de quintas folhas colhidas na haste principal de, aproximadamente, trinta plantas por parcela, no florescimento, conforme HIROCE et al. (1976). Tentou-se uma análise conjunta, reunindo ensalos basicamente pelo teor de $B$ no solo, mas considerando-se também outros fatores, tais como intensidade de cultivo e de adubação e ocorrência de sintomas de deficiência ou de toxicidade do micronutriente. Dentro de cada grupo, procedeu-se a uma análise econômica simplificada. Assim, retiraram-se da receita bruta, calculada em função da produtividade e do preço atualizado do algodão em caroço (Cr $\$ 40,00 / \mathrm{kg})$, o preço atualizado do boro $(\mathrm{Cr} \$ 1.044,00 / \mathrm{kg})$ e a despesa com a colheita do acréscimo de produção devido à adubação (cerca de 1/5 do preço do algodão).

Em amostras de solo, constituídas de quinze a vinte subamostras, retiradas a $0-20 \mathrm{~cm}$ nas glebas experimentais, efetuaram-se análises de $B$ no solo, utilizando como extratores a água quente e a solução de Mehlich $\left(\mathrm{HCl} 0,05 \mathrm{M}+\mathrm{H}_{2} \mathrm{SO}_{4}\right.$ $0,0125 \mathrm{M}$ ). A determinação colorimétrica realizou-se com azometina H (BATAGLIA \&RAIJ, 1990) ea do micronutriente no limbo foliar, por sua vez, conforme BATAGLIA et al. (1983).

\section{RESULTADOS E DISCUSSÃO}

\subsection{Análise do solo}

No quadro 1 estão relacionados os municípios onde se instalaram os ensaios e os resultados de análise das respectivas amostras de solo.

Observa-se que, a partir de 1983, houve uma variação na apresentação dos resultados, decorrente de modificações introduzidas na rotina de trabalho do laboratório do Instituto Agronômico (RAIJ \& QUAGGIO, 1983). Assim, foram modificadas as determinações de $\mathrm{pH}$ e de $\mathrm{P}$ e introduzida a do $(\mathrm{H}+\mathrm{Al})$, o que permitiu os cálculos da CTC e V\%. Nota-se, ainda, que para alguns ensaios não se determinou boro, por impossibilidade de recuperação de todas as amostras de solo.

As áreas experimentais, em geral, mostravam-se medianamente corrigidas no aspecto de acidez, exceção feita ao solo argiloso de Bernardino de Campos (ensaio n. 8) e, em menor escala, ao de Conchal (n. 9). O teor de P, que, em geral, variou de médio a alto, comprova, de certo modo, a tradição de cultivo das glebas estudadas e 0 acúmulo de fertilizantes. Nesse aspecto, os solos mais arenosos da região oeste (ensaios n. ${ }^{\circ \mathrm{s}} 3,4 \mathrm{e} 6$ ) constituem exceção, pois anteriormente estavam cobertos por pastagens pouco ou raramente adubadas, assim como o de Conchal (ensaio n. 9), em fase de recuperação, e a gleba de cerrado recém-derrubado, de Agual (ensaio n. 5). O teor de matéria orgânica mostrou-se bastante variável (entre 1,6 e 5,9\%) e, na medida em que pode refletir a textura dos solos cultivados em dada região (LEPSCH et al., 1982), indica que foram utilizadas desde glebas 


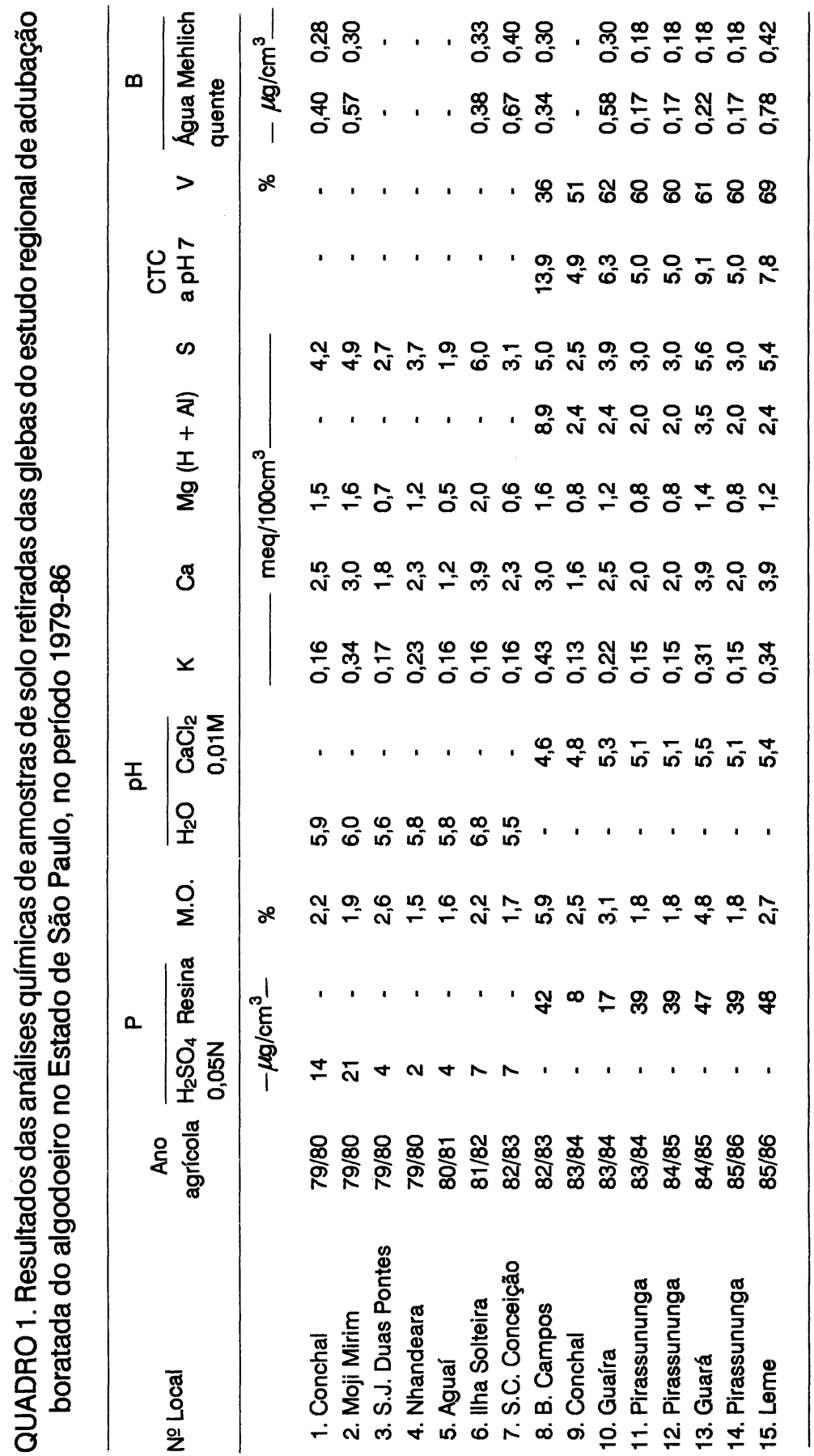


argilosas/muito argilosas (ensaios $n_{0}^{0 s} 8,10$ e 13), até outras com textura média/arenosa (ensaios n. $3,4,11,12$ e 14). Quanto ao boro, a variabilidade observada em seu teor, desde 0,17 até $0,78 \mathrm{ppm}$ de $B$ em água quente, mostrou-se quase tão ampla quanto a relatada por BATAGLIA \& RAIJ (1990), trabalhando com diversos solos paulistas $(0,12$ a $0,71 \mathrm{ppm}$ de $B)$, ou por SEDBERRY JR. et al. (1969), utilizando quase meia centena de ensaios na Louisiana, EUA $(0,12$ a 0,60ppm de B). Como não foi possível determinar o boro nos solos de todos os experimentos, esses resultados não constituíram critério único para a separação dos ensaios por faixa de expectativa de resposta. O histórico das glebas, que levou em conta principalmente a intensidade de cultivo e o uso de calcário e de adubos nas áreas estudadas, assim como a ocorrência de sintomas de carência ou de toxicidade, foram também considerados na constituição de cada grupo que, por convenção, passa a ser simbolizado pela sigla $\mathrm{Gr}$.

O grupo considerado como o de resposta esperada mais alta - Gr.1 constituiu-se de ensaios em solos corrigidos no aspecto de acidez, intensamente cultivados e adubados com NPK, mas que ainda não haviam recebido boro. Dele fazem parte os três estudos em solo de textura média, no município de Pirassununga ( $n^{\circ s} 11,12$ e 14), com $0,17 \mathrm{ppm}$ de $B$ na análise, em água quente; neles ocorreram os maiores sintomas de deficiência de boro nas parcelas testemunhas: ponteiros cloróticos; flores defeituosas e "shedding" anormal; anéis concêntricos no pecíolo foliar; superbrotamento e atraso no ciclo (SILVA et al., 1982). Encontra-se nesse grupo, também, o ensaio de Guará ( $n^{\circ}$ 13), que, embora tenha sido efetuado em solo argiloso (alto teor de $\mathrm{M} 0 \%$ ), apresentou teor de boro relativamente baixo $(0,22 \mathrm{ppm}$ de $\mathrm{B}$ em água quente). Os sintomas de carência foram semelhantes, porém detectados em menor escala. SEDBERRY JR. et al. (1969) e MURPHY \& LANCASTER (1971) indicam como nível crítico para o algodoeiro valores entre 0,19 e 0,16ppm de $B$ solúvel em água quente.

No outro extremo, reuniram-se os ensaios tidos como de resposta esperada mais baixa - Gr.4 - por terem sido realizados sobre solos em pousio (pastagens antigas), pouco adubados quimicamente e onde foram observados sintomas de toxicidade devidos aos elevados teores de $\mathrm{B}$, tais como menor desenvolvimento das plantas e certa redução do ciclo vegetativo. Foram reunidos, nesse grupo, os experimentos 3,4 e 6 , que representavam gleba de textura mais leve (média/arenosa), com uma única determinação de boro no solo: $0,38 \mathrm{ppm}$ de $\mathrm{B}$ em água quente (ensaio 6, quadro 1).

Na faixa considerada intermediária, reuniram-se os ensaios em solos em fase de correção da acidez, cultivados e adubados com N, $\mathrm{P}$ e K, porém pouco ou nunca adubados com boro, que abrangeram os municípios de Conchal (n.8 1 e 9), Moji Mirim (n. 2), Bernardino de Campos ( $\left.n^{\circ} 8\right)$ e Guaíra (n. 10). A textura mostrou-se variável entre média e argilosa, e o teor de boro do solo solúvel em água quente, entre 0,34 e 0,58ppm de B. Na escala de resposta esperada, constituem o segundo grupo - Gr. 2 - onde se observaram sintomas de deficiência do micronutriente, semelhantes aos descritos em Gr. 1. 
Por fim, tem-se o grupo de ensaios em solos corrigidos, cultivados e adubados inclusive com boro - Gr. 3 - nos municípios de Aguaí, Santa Cruz da Conceição e Leme ( $n^{0 s} 5,7$ e 15). A textura variou de média a argilosa e o teor do micronutriente na análise de terra esteve entre 0,67 e 0,78ppm de $B$ solúvel em água, o que parece refletir o uso anterior do micronutriente na adubação.

\subsection{Efeitos sobre a produção}

No quadro 2, encontram-se os resultados médios de produção de algodão em caroço obtidos por dose de adubação boratada e os respectivos dados de análise da variância, de cada um dos quinze experimentos.

Nas análises individuais, observa-se que o efeito do boro foi significativo somente nos ensaios de Pirassununga (n.8 11,12 e 14), ou seja, em apenas $20 \%$ dos casos. Na verdade, o efeito médio da adubação foi sempre positivo, com acréscimos variando entre 8 e 587kg/ha de algodão em caroço, aproximando-se os índices mais altos dos valores obtidos por CARVALHO (1980) e SILVA et al. (1982), em condições onde se observava deficiência. Em dois casos isolados, Nhandeara (ensaio 4) e Agual (ensaio 5), no entanto, constataram-se decréscimos na produtividade, de 117 e $200 \mathrm{~kg} / \mathrm{ha}$, respectivamente, devidos às doses de 0,2 e $3,2 \mathrm{~kg} / \mathrm{ha}$ de $B$ em relação à testemunha. A propósito, SEDBERRY JR. et al. (1969), aplicando $1,1 \mathrm{~kg} / \mathrm{ha}$ de $B$ em 49 ensaios na Louisiana, EUA, obtiveram resultados positivos e significativos em apenas $6 \%$ dos casos, enquanto, em cerca de $18 \%$ deles, houve decréscimos de produção, entre 100 e $200 \mathrm{~kg} / \mathrm{ha}$ de algodão em caroço. FRITZ (1971), testando doses crescentes de boro $(0,17$ a 2,86kg/ha de B), em sete experimentos de campo na África, obteve efeito sobre a produção de algodão em apenas um deles, embora a adubação nunca tenha reduzido a produtividade. MURPHY \& LANCASTER (1971), aplicando boro $(0,29$ a 1,14kg/ha de B) em algodão cultivado sobre solos corrigidos (pH ao redor de 7,0) no Mississípi, conseguiram resultados positivos e significativos em três dos seis ensaios.

$\mathrm{Na}$ análise conjunta (Quadro 2), nota-se que o efeito dos tratamentos sobre a produtividade foi estatisticamente significativo $\left(F=5,17^{\star *}\right)$, com aumentos médios superiores a $8 \%$ nas doses intermediárias e um leve declínio na dose máxima (3,2kg/ha de B). No entanto, em função das múltiplas condições em que foi realizado o presente estudo, obteve-se valor $F$ relativamente alto para interação tratamentos $x$ localidades, de $1,75^{\star \star}$. Por essa razão, os ensaios foram divididos em grupos com condições mais homogêneas, estando os resultados no quadro 3.

Com o reagrupamento dos dados de produção, percebe-se que a interação tratamentos $x$ localidades passou a ser não significativa, e que o efeito de boro variou em função dos grupos constituídos. Assim, valores significativos de $F$ para tratamentos foram obtidos nos grupos $1 \mathrm{e} 2$, de mais altas respostas esperadas das plantas à adubação, enquanto a reação do algodoeiro em termos de produtividade foi menor nos demais grupos. De modo geral, a produção das plantas cresceu 


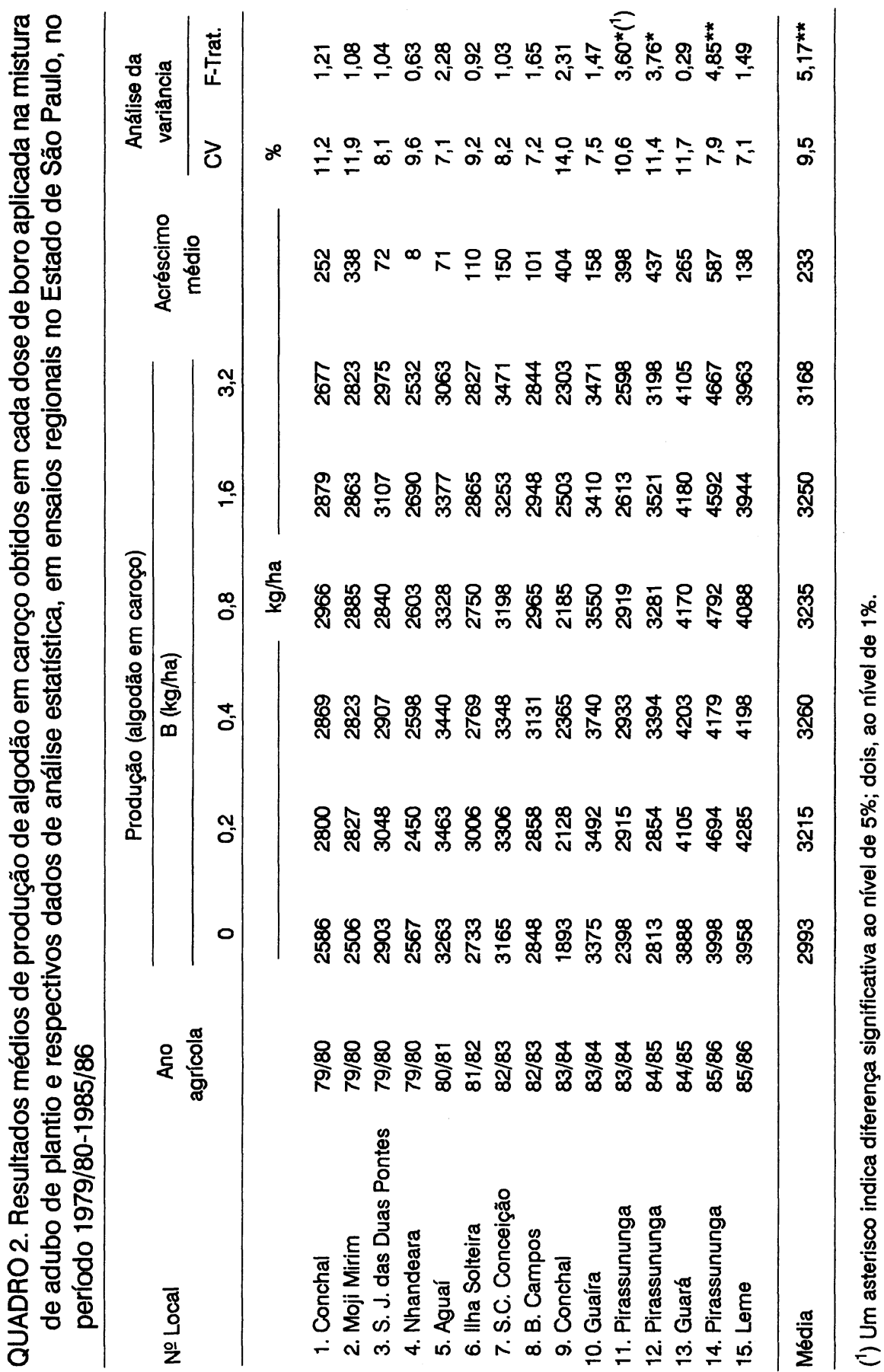




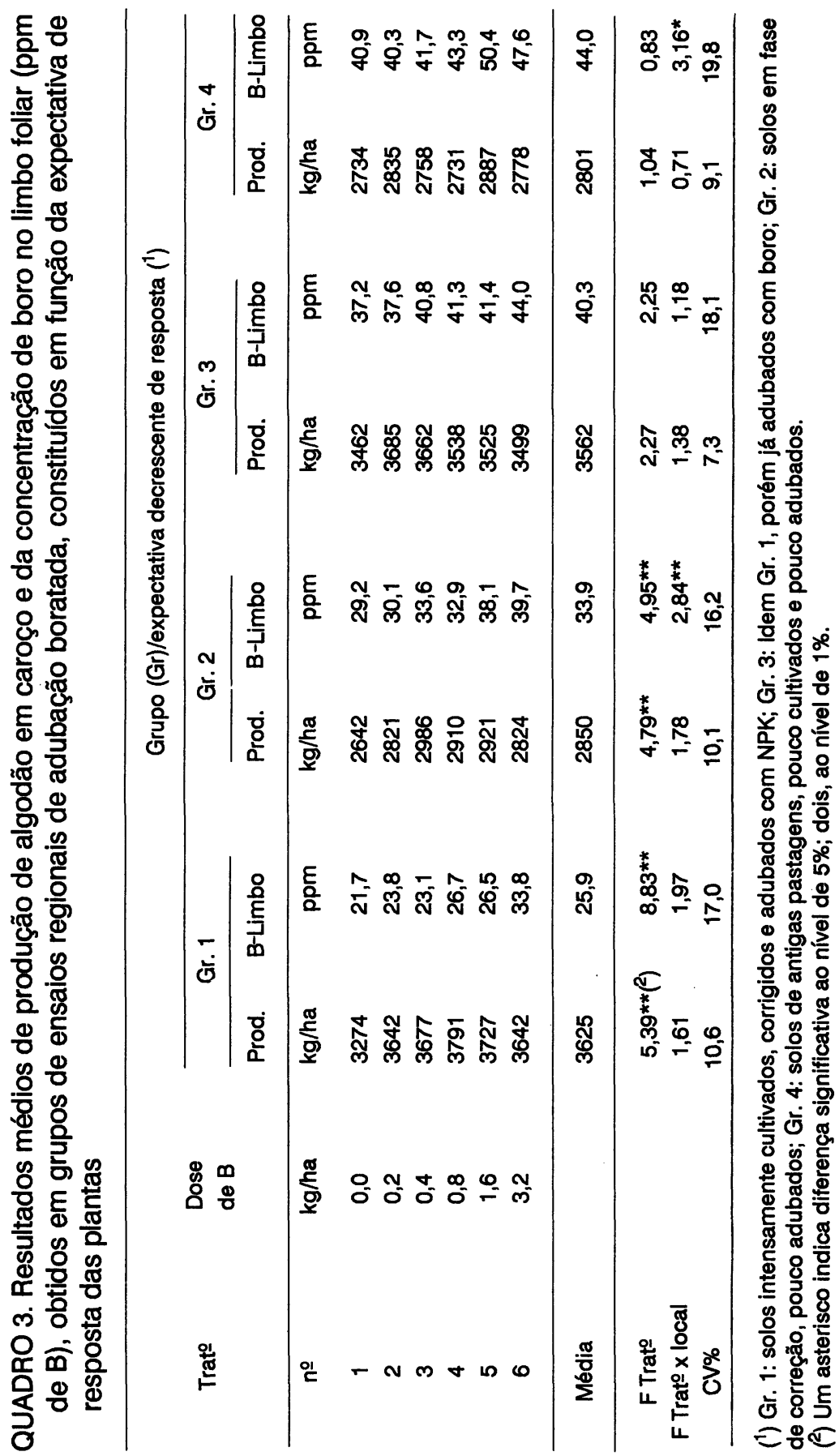


sensivelmente com as primeiras doses do micronutriente, caindo de modo gradativo com as doses maiores. Esse tipo de resposta, típica de nutrientes que se tornam tóxicos em função da quantidade utilizada, ficou bem caracterizado com a análise econômica dos resultados, efetuada dentro de cada grupo - Figura 1.

A primeira vista, nota-se que nos grupos referentes a solos corrigidos por calagem e adubação mineral NPK (Gr. 1 e Gr. 3), o algodoeiro proporcionou uma receita mais destacada do que nos solos em fase de correção e/ou pouco adubados com NPK (Gr. 2 e Gr. 4), em conseqüência dos níveis de produtividade expostos no quadro 3. Nos solos cultivados, nunca ou raramente adubados com boro (Gr. 1 e Gr. 2), no entanto, o efeito da adubação foi maior, ajustando-se bem, as curvas de respostas da receita líquida, ao modelo da raiz quadrada: $y=a+b x+c \sqrt{x}$, onde y representa a receita e $x$, a dose de adubo ( $\mathrm{kg} / \mathrm{ha}$ de $B)$.

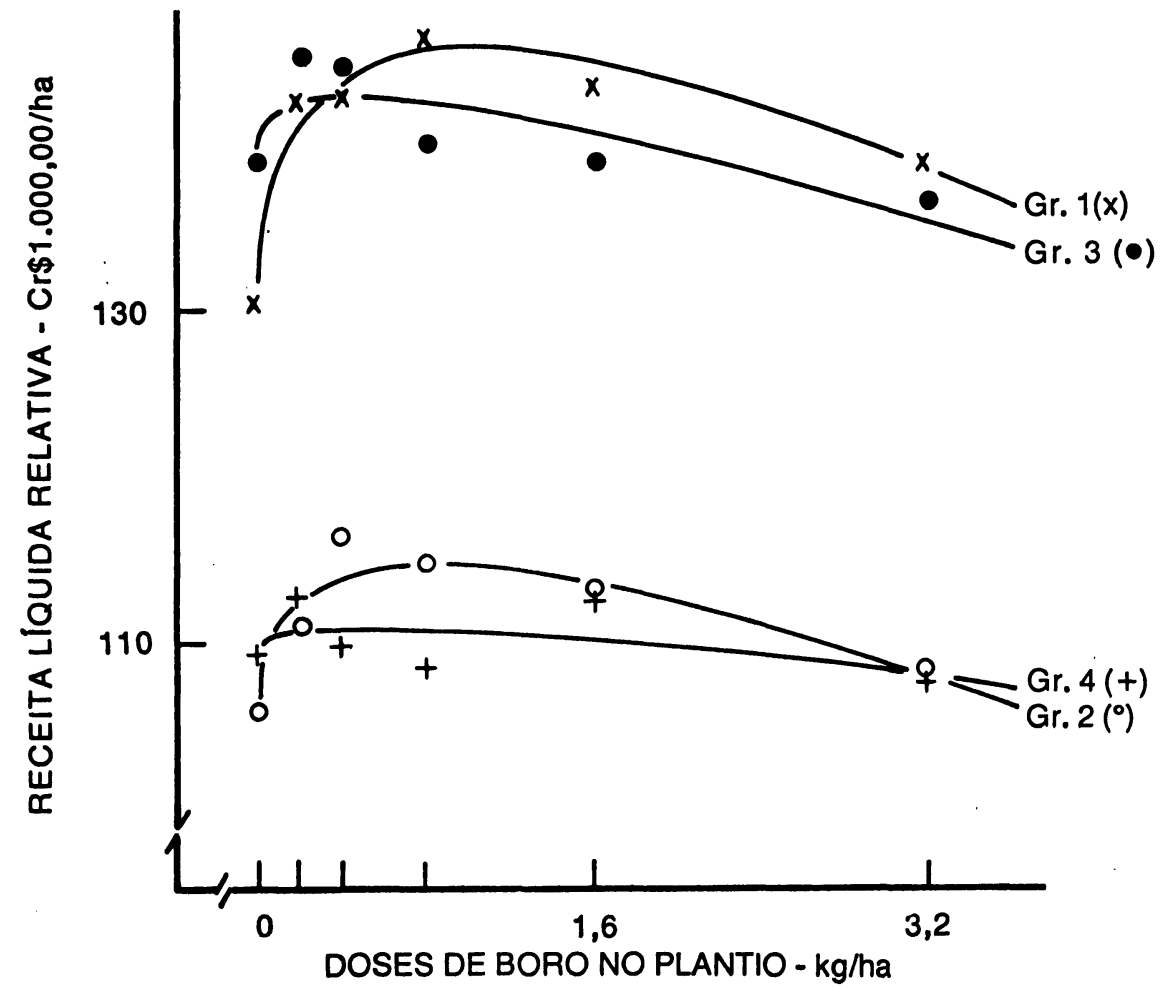

FIGURA 1. Representação gráfica da equação de regressão entre a receita líquida relativa (y), calculada em função da produção, e a raiz quadrada das doses de boro $(x)$ fornecidas na adúbação de plantio, obtida para os diferentes grupos (Gr.) de ensaios com o algodoeiro no Estado de São Paulo: Gr. 1, de solos corrigidos e adubados com NPK $(n=4)$, com y = 131,54 $13,29 x+27,8345 \sqrt{x}$ e $R=0,980^{\star *} ;$ Gr. 3 , idem $\mathrm{Gr}$. 1, porém já adubados com boro $(n=3)$, com $y=140,12-5,91 x+7,8560 \sqrt{x} \in R=0,790 ; G r .2$, de solos em fase de correção, pouco adubados ( $n=5)$, com $y=105,90-9,64 x+18,2964 \sqrt{x}$ e $R=0,931 *$, $\theta \mathrm{Gr}$. 4, de solos em pousio ou pouco cultivados $(n=3)$, com $y=109,51-2,48 x+3,6258 \sqrt{x}$ e $R=0,590$. 
No caso do grupo de mais alta resposta esperada (Gr. 1), obteve-se ponto de máxima receita com a dose $1,1 \mathrm{~kg} / \mathrm{ha}$ de $B$, enquanto no segundo (Gr. 2), o valor esteve em torno de $0,9 \mathrm{~kg} / \mathrm{ha}$. SILVA et al. (1982), trabalhando em condições semelhantes às do grupo Gr. 1, determinaram a dose de $1,23 \mathrm{~kg} / \mathrm{ha}$ de $B$ como a mais econômica, enquanto no estudo de CARVALHO (1980) aquela dose esteve entre 1,1 e 1,4kg/ha de $B$, em função da quantidade de calcário usada. No ensaio de campo com efeito significativo da adubação boratada (FRITZ, 1971), o maior aumento de produção, da ordem de $398 \mathrm{~kg} / \mathrm{ha}$ de algodão em caroço, foi devido à dose de $1,43 \mathrm{~kg} / \mathrm{ha}$ de $B$. Já nos três experimentos de MURPHY \& LANCASTER (1971), houve crescimento da produção até o nível de 1,14kg/ha de B, embora os acréscimos devidos às doses inferiores $(0,29 \mathrm{e}, 5,5 \mathrm{~kg} / \mathrm{ha}$ de $B)$ não tenham diferido estatisticamente. Em recente trabalho, CARVALHO (1988) observou que a produção de algodão cresceu até a dose de $1,5 \mathrm{~kg} / \mathrm{ha}$ de $B$, em solos cuja deficiência de B nas plantas já havia sido observada.

Nos solos cultivados, porém já adubados com boro no presente estudo (Gr. 3), a correlação entre as doses de adubo e a resposta da planta foi menor, embora ainda persista a tendência quadrática da curva, conforme figura 1 . 0 ponto de máxima esteve em torno de $0,5 \mathrm{~kg} / \mathrm{ha}$ de B. Por fim, nas glebas ocupadas anteriormente por antigas pastagens (Gr. 4), a reação das plantas foi inexpressiva, mesmo nos niveis mais baixos de fertilização. Aliás, nesses dois últimos grupos, notou-se um declínio mais acentuado na curva de resposta, devido às doses maiores de boro.

\subsection{Concentração de B na folha}

Os resultados médios do teor de boro no limbo foliar, obtidos em onze dos quinze ensaios, assim como as respectivas análises da variância, são apresentados no quadro 4.

Nas análises individuais, nota-se que o algodoeiro reagiu mais à adubação em termos de concentração de boro no limbo do que em relação à produtividade. Com efeito, em mais de $50 \%$ das análises foliares, a ação do boro foi significativa, com acréscimos médios variando entre $0,5 \mathrm{ppm}$ de $B(+2 \%)$, obtido no ensaio 3 , de solo arenoso pouco cultivado, e $8,5 \mathrm{ppm}$ de $B(+51 \%)$, no ensaio sobre solo corrigido e intensamente cultivado e adubado com NPK (n. 12). Sintomas de deficiência, como os descritos no item 3.1., foram observados com freqüência nos ensaios n.os 11,12 e 14 (Gr. 1), em especial nas parcelas testemunhas que, por sinal, apresentaram as menores médias de boro na folha, respectivamente, 26,3, 16,7 e 22,0ppm de B. Em escala menor, constatou-se carência de boro também nas parcelas sem adubo dos ensaios 7 (Gr. 1), 8 e 10 (Gr. 2), respectivamente, com médias de $31,0,23,7$ e $24,7 \mathrm{ppm}$ de $B$. Nos primeiros sintomas de deficiência observados em São Paulo, os valores de análise foliar estiveram abaixo de 20ppm (COSTA et al., 1976). SILVA et al. (1982) e CARVALHO (1988), trabalhando em condições de deficiência, verificaram, nas parcelas sem adubo, que a concentração 


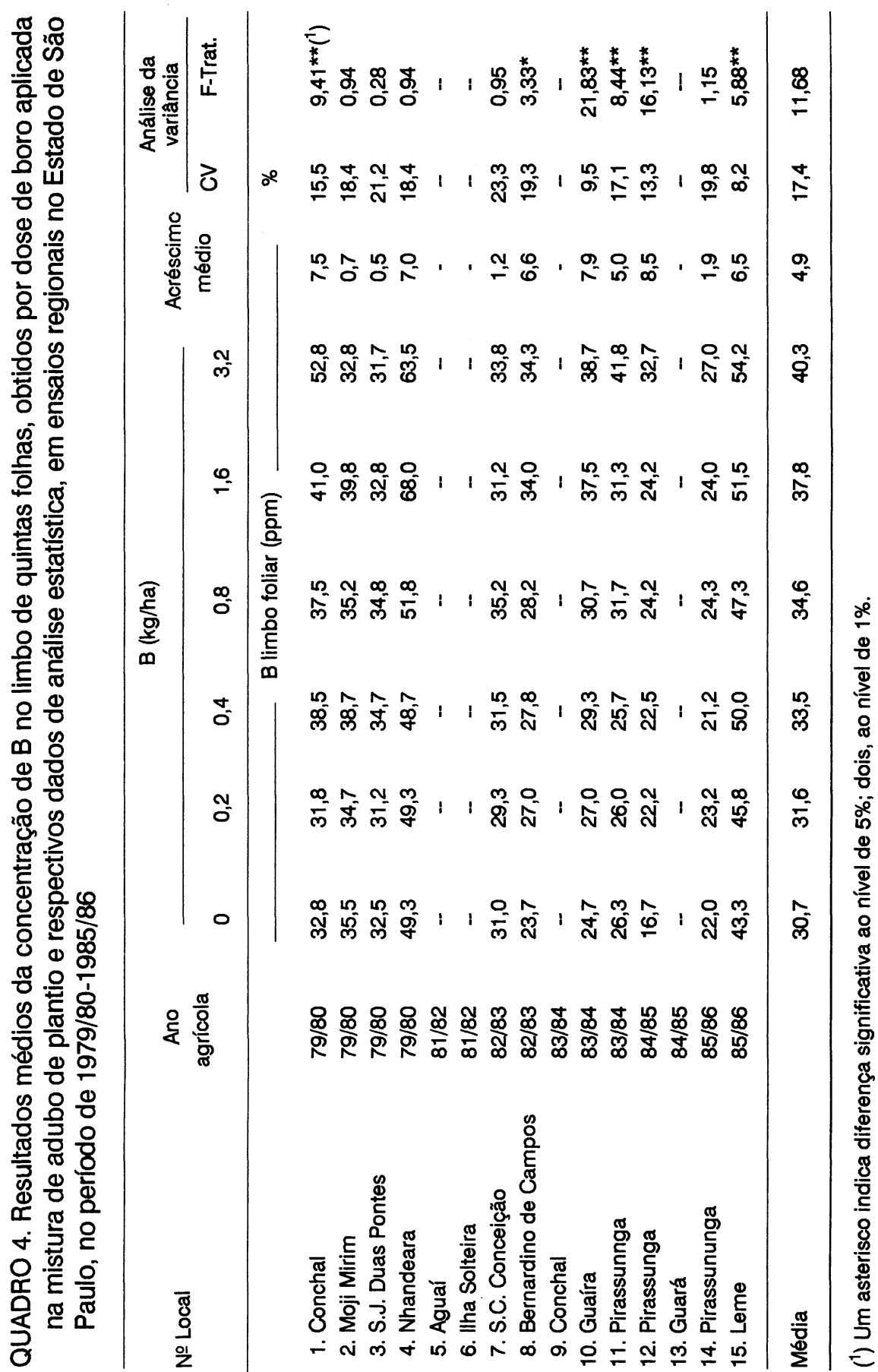


de boro na folha variou entre 15 e 40ppm no primeiro caso e entre 20 e 40ppm, no segundo. Já SEDBERRY JR. et al. (1969), nos ensaios com altas respostas ao boro, notaram que no limbo da primeira folha madura, colhida na haste principal das plantas testemunhas, a concentração variou entre 7 e $30 \mathrm{ppm}$ de $B$.

Alguns sintomas de toxicidade, expressos em termos de menor desenvolvimento das plantas e do encurtamento do ciclo, foram observados nas parcelas com adubação máxima, nos ensaios 4 e 6, conduzidos sobre solos mais arenosos e pouco cultivados. Amostras de folhas coletadas no primeiro ensaio acusaram, nas doses de 1,6 e 3,2kg/ha de $B$, os maiores valores médios das análises foliares efetuadas, respectivamente, 68,0 e 63,5ppm de B. Entretanto, nenhuma anomalia foi constatada nos experimentos sobre solos de textura média (n.s 1 e 15), onde também o teor de boro na dose máxima alcançou Indices consideráveis, respectivamente de 52,8 e 54,2ppm de B. SILVA et al. (1979) relacionaram os sintomas iniciais de intoxicação a valores superiores a $46 \mathrm{ppm}$ de $B$, na quinta e na sexta folhas, em estudo de casa de vegetação. SEDBERRY JR. et al. (1969), embora não tenham descrito sintomas de toxicidade, acusaram freqüente decréscimo de produção de algodão com o uso de boro, quando os resultados da análise quimica da primeira folha madura ultrapassavam a faixa de 40-50ppm de $B$.

$\mathrm{Na}$ análise conjunta dos dados, obteve-se efeito altamente significativo da adubação, conforme a última linha do quadro 4 . Os acréscimos de $3,9,13,23$ e $31 \%$, correspondentes, respectivamente, às doses de 0,$2 ; 0,4 ; 0,8 ; 1,6$ e 3,2kg/ha de $B$, demonstraram que a concentração de $B$ no limbo cresceu de modo linear com o emprego do micronutriente. Ao se reunirem os ensaios quanto à expectativa de resposta, nota-se que o algodoeiro teve comportamento diferenciado conforme o grupo, de acordo com os resultados do quadro 3. Percebe-se que o valor de $F$ de tratamentos caiu gradativamente do grupo de maior resposta esperada (Gr. 1) para o de menor (Gr. 4). Um estudo de correlação entre as doses de adubo (x) e a concentração de boro no limbo (y) esclarece melhor esse relacionamento, cujas curvas se acham na figura 2.

No grupo de mais alta resposta esperada (Gr. 1), a correlação foi altamente significativa e de natureza linear. $O$ teor médio no tratamento testemunha foi de $21,7 \mathrm{ppm}$ de $\mathrm{B}$, confirmando o índice entre 20 e 25ppm, indicado como critico por MURPHY \& LANCASTER (1971) para a análise da quinta e sexta folhas a partir do topo, na haste principal do algodoeiro.

No grupo de ensaios em solos em fase de recuperação (Gr. 2), a correlação mostrou-se igualmente significativa e de natureza linear. Nesse caso, no entanto, a concentração de boro no limbo foliar do tratamento testemunha alcançou índice médio mais elevado (29,6ppm de B). Nos solos onde o micronutriente já havia sido acumulado em adubações anteriores (Gr. 3), os aumentos na concentração foram menores, embora ainda significativos e de natureza linear. Por fim, no grupo de solos pouco cultivados e de baixa resposta esperada (Gr. 4), a reação da planta à aplicação de boro, em termos de concentração na folha, foi de natureza quadrática, 
com ponto de máxima na curva de resposta ao redor de 50ppm de B, para a dose de 2,3kg/ha de B, na adubação. O valor para a testemiunha se acercou de $40 \mathrm{ppm}$ de $B$, à semelhança do grupo anterior (Gr. 3).

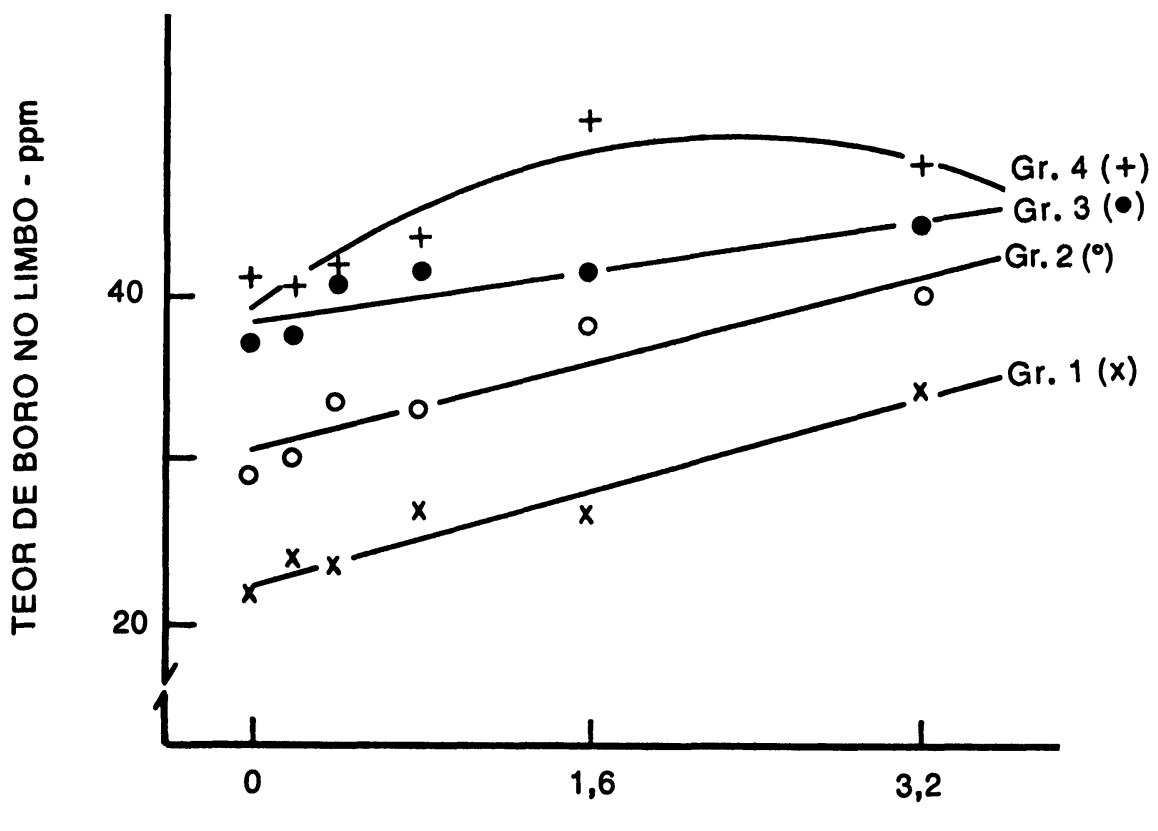

DOSES DE BORO NO PLANTIO - $\mathrm{kg} / \mathrm{ha}$

FIGURA 2. Concentração média de boro no limbo foliar $(y)$ em função das doses de boro fornecidas na adubação de plantio (x), nos diferentes grupos (Gr.) de ensaios com o algodoeiro no Estado de São Paulo: Gr. 1, de solos intensamente cultivados, corrigidos e adubados com NPK $(n=3)$, com y $=22,3+3,48 x$ er $=0,968 * *$; Gr. 3, idem Gr. 1, porém já adubados com boro $(n=2)$, com y $=38,5+1,89 x$ er $=0,877^{*} ; \mathrm{Gr} .2$, de solos em fase de correção, pouco adubados ( $n=4)$, com $y=30,6+3,23 x$ er $=0,923^{*}$, e Gr. 4, de solos em pousio ou pouco cultivados $(n=2)$ com $y=39,2+8,94 x+19,421 x^{2}$ e $R=0,933^{*}$.

\subsection{Faixas críticas para recomendação}

Efetuou-se estudo de correlação entre os resultados de B no solo, extraído por solução de Mehlich ou por água quente (Quadro 1), e os acréscimos sobre a produção da testemunha, devidos à média dos tratamentos adubados (Quadro 2). $\mathrm{Na}$ figura 3, são apresentadas as curvas obtidas em cada caso. 
Observa-se que os acréscimos de produção de algodão decrescem significativamente com o aumento da concentração de boro no solo, em especial para extração com água quente. Embora no aspecto estatístico não tenha havido diferença significativa entre os métodos, a água quente parece discriminar mais eficientemente a melhoria do solo, em termos da concentração de boro, desde que possibilita maior amplitude de variação dos resultados, conforme já detectado por BATAGLIA \& RAIJ (1990).

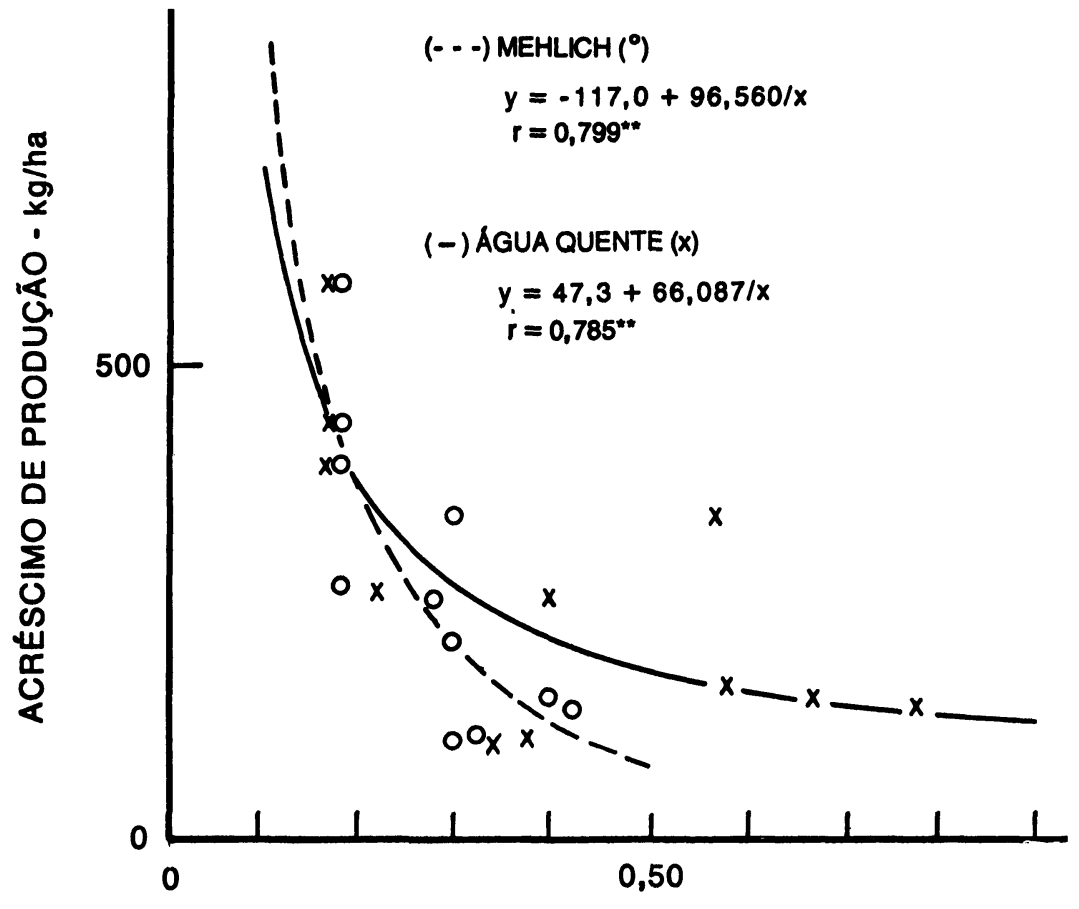

TEOR DE BORO NO SOLO -'ppm

FIGURA 3. Acréscimos de produção (kg/ha de algodão em caroço) devidos à adubação boratada média, em função do teor do micronutriente no solo, extraído pelos métodos de Mehlich e da água quente, em onze ensaios de adubação com o algodoeiro no Estado de São Paulo, entre 1979 e 1986.

Ainda nessa figura, nota-se que, abaixo de 0,20ppm de B (água quente), a produção de algodão aumentou sensivelmente em função da concentração do micronutriente no solo, enquanto acima de $0,40 \mathrm{ppm}$ de $B$, os acréscimos tenderam a estabilizar-se. Como primeira aproximação, pode-se considerar essa faixa como indicadora de necessidade de adubação boratada do algodoeiro. Valores de 
análise de terra situados abaixo dessa falxa referenclal indicariam a necessidade de adubação corretiva; quando dentro dela, uma adubação corretiva, em escala menor, poderia evitar o aparecimento de deficiência, enquanto em valores acima de $0,40 \mathrm{ppm}$ de B, uma adubação imediata seria dispensável. BATAGLIA \& RAIJ (1990), trabalhando em vaso com girassol, chegaram tentativamente a indices muito próximos dos aqui considerados $(0,20$ a 0,50ppm de B).

Os acréscimos de produção devidos ao uso de boro correlacionaram-se de modo significativo, também, com os valores médios da concentração de B no limbo foliar das parcelas testemunhas, embora com mais baixo coeficiente de determinação. A natureza da curva que expressa essa relação assemelha-se bastante à do estudo anterior, conforme figura 4: nota-se que a reação do algodoeiro à adubação cai à medida que cresce a concentração de boro no limbo foliar de plantas testemunhas. Associando-se a esse estudo as considerações feitas no item 3.3., pode-se tentativamente indicar a faixa de 25 a $40 \mathrm{ppm}$ de $B$ no limbo da quinta folha como referencial da necessidade de boro pelo algodoeiro, a exemplo do que foi feito para análise do solo.

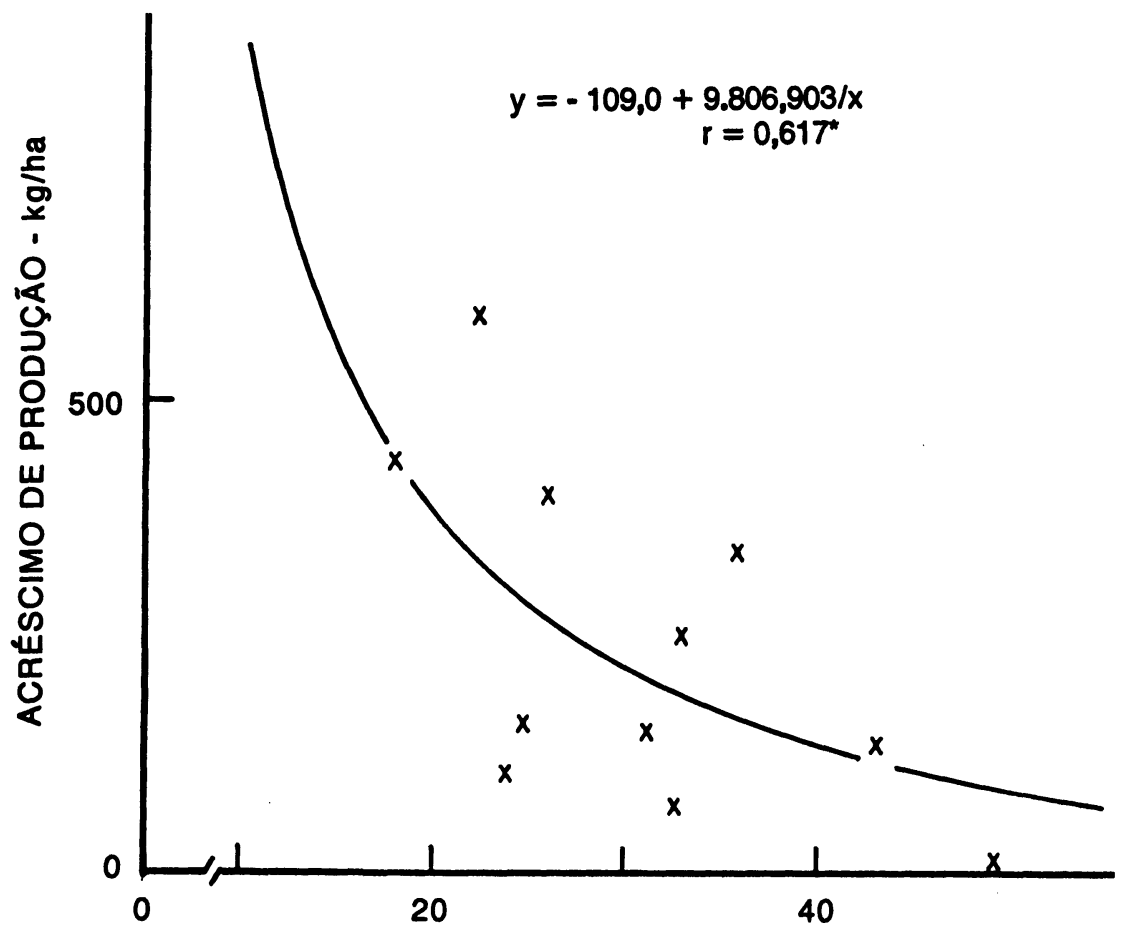

TEOR DE BORO NO LIMBO - ppm

FIGURA 4. Relação entre a concentração de boro no limbo de quintas folhas, colhidas nas parcelas testemunhas, e os acréscimos de produçăo devidos à adubaçăo boratada média, observada em onze ensaios com o algodoeiro no Estado de São Paulo, entre 1979 e 1986. 


\section{CONCLUSÓES}

1. Nos solos cultivados do Estado de São Paulo, o algodoeiro freqüentemente reage de modo favorável à aplicação de boro na adubação de plantio.

2. Embora os dados das análises de solo e de folhas se tenham revelado bons indicadores das necessidades da planta, discriminando bem o efeito da adubação boratada, a reunião dos ensaios em função de informações do histórico das glebas estudadas, associadas à ocorrência de sintomas de deficiência ou de toxicidade de boro, permitiu prever a possibilidade de resposta à aplicação de boro.

3. As mais altas produtividades foram obtidas em solos tradicionalmente cultivados e adubados e com a acidez corrigida, destacando-se o efeito do micronutriente nos solos corrigidos e adubados com NPK; esse efeito diminuiu nas glebas em fase de correção ou que já haviam recebido adubação boratada $e$, praticamente, se anulou nos solos de antigas pastagens, pouco cultivados.

4. Os acréscimos de produção se correlacionaram significativamente com o teor de B extraldo do solo pela solução de Mehlich, em especial com água quente, havendo boa correlação, também, com a concentração de boro no limbo foliar.

5. Para os solos cultivados de São Paulo, propõe-se, tentativamente, que se adotem as faixas entre 0,20 e 0,40ppm de B no solo (água quente) e entre 25 e 40ppm de $B$ no limbo da quinta folha, como indicadores da necessidade do uso de boro na adubação do algodoeiro.

\section{AGRADECIMENTOS}

Agradecimentos são devidos aos Eng.'-Agr.os Nicanor Carvalho, José A. Correa, José Viotti e Paulo H. Mafud, pela colaboração na execução dos experimentos.

\section{REFERÊNCIAS BIBLIOGRÁFICAS}

BATAGLIA, O.C; FURLANI, A.M.C.; TEIXEIRA, J.P.F.; FURLANI, P.R. \& GALLO, J.R. Métodos de análise química de plantas. Campinas, Instituto Agronômico, 1983. 48p. (Boletim técnico, 78)

\& RAIJ, B. van. Eficiência de extratores na determinação de boro em solos. Revista Brasileira de Ciência do Solo, Campinas, 14(1):25-31, 1990.

CARVALHO, L.H. Aplicaçāo de boro na cultura do algodoeiro (Gossypium hirsutum L var. latifolium Hutch.). Piracicaba, ESALQ/USP, 1988. 76p. Tese (Doutorado).

Efeltos da calagem e da adubaçăo boratada sobre o algodoelro (Gossypium hirsutum L) cultivado em Latossolo Vermelho Amarelo-fase arenosa. Piracicaba, ESALQ/USP, 1980. 64p. Tese (Mestrado).

COSTA, A.S.; CARVALHO, N.; GALLO, J.R. \& COSTA, D.S. Deficiência de boro, anomalia do algodoeiro em São Paulo que se assemelha a uma virose. In: CONGRESSO ANUAL DA SOCIEDADE BRASILEIRA DE FITOPATOLOGIA, 9., Campinas, 1976. Fitopatologla, Lima, 11 (1):10-11, 1976. Resumo. 
FRITZ, A. La déficience en bore du cotonnier au Nord-Cameroun. Coton et Fibres Troplcales, Paris, 26(2):235-241, 1971.

HINKLE, D.A. \& BROWN, A.L. Secondary nutrients and micronutrients. In: ADVANCES in production and utilization of quality cotton-principles and practices. Ames, lowa State University Press, 1966. p.280-366.

HIROCE, R.; SILVA, N.M. da; NAGAI, V.; BATAGLIA, O.C. \& GALLO, J.R. Diagnose da nutriçăo nitrogenada $\theta$ potássica do algodoeiro (Gossyplum hirsutum 'IAC 13-1') pela análise química foliar. Clência e Cultura, São Paulo, 28(1):51-56, 1976.

LEPSCH, I.F.; SILVA, N.M. da \& ESPIRONELO, A. Relaçăo entre matéria orgânica e textura de solos sob cultivo de algodão e cana-de-açúcar, no Estado de São Paulo. Bragantia, Campinas, 41:231-236, 1982. (Nota, 8)

MURPHY, B.C. \& LANCASTER, J.D. Response of cotton to boron. Agronomy Journal, Madison, 63(4):539-540, 1971.

RAIJ, B. van \& QUAGGIO, J.A. Métodos de anállse de solo para fins de fertilldade. Campinas, Instituto Agronômico, 1983. 31p. (Boletim técnico, 81)

SEDBERRY JÚNIOR, J.E.; NUGENT, A.L.; BRUPBACHER, R.H.; HULDER, J.B.; PHILLIPS, S.A.; MARSHALL, J.G.; SLOANA, L.W.; MELVILLE, D.R. \& RABB, J.L. Boron investigation with cotton in Loulsiana. Baton Rouge, Louisiana Agricultural Experiment Station, 1969. 27p. (Bulletin, 635)

SILVA, N.M. da; CARVALHO, L.H.; BATAGLIA, O.C. \& HIROCE, R. Efeitos do boro em algodoeiro cultivado em condições de casa de vegetação. Bragantia, Campinas, 38:153-164, 1979.

- ; - CHIAVEGATO, E.J.; SABINO, N.P. \& HIROCE, R. Efeito de doses de boro aplicadas no sulco de plantio do algodoeiro, em solo deficiente. Bragantia, Campinas, 41:181-191, 1982. 